\title{
The Effectiveness of Financial Supervision Frameworks
}

\author{
Wook Sohn \\ KDI School of Public Policy and Management \\ Iegor Vyshnevskyi \\ National Bank of Ukraine
}

This paper examines the effectiveness of five types of financial supervisory frameworks by using 49 member countries of the G20 and/or OECD for the period of 1997-2015. We find that the effectiveness, proxied by the probability of default of a country's banking system, of the hybrid supervisory model is statistically higher than that of the institutional (sectoral) framework. This result suggests that no single financial supervisory model is superior to all others, and creating the best model may require some adjustment of the typical four models.

Keywords: financial supervisory framework, institutional (sectoral) model, integrated model, twin peaks model, functional model, hybrid model

\section{INTRODUCTION}

Financial supervisory structures vary widely across the globe because of countries' historical, political, economic and financial dissimilarities. Consequently, there is no one model to be chosen for every country even though supervisory systems in different countries are dealing with similar issues. ${ }^{1}$ In 2008, a G30 report identifies four models of financial supervision in use across the globe, namely the institutional (sectoral), functional, integrated, and twin peaks models. In our study, we use this system of classification and add a hybrid approach that is a combination of the other four models.

The institutional model is an approach driven by the legal status of the object of supervision (entity). Hence, the entity's legal status (for instance, a bank, insurance company, or securities firm) determines which authority has the duty of supervising its activity from prudential and business conduct perspectives. Under the functional model, each type of business activity within an entity is supervised by different authorities regardless of the entity's legal status. For instance, if a company performs banking, insurance, and securities activities, each would be supervised by a separate regulator responsible for both prudential and business conduct regulation. Under the integrated approach, there is one common authority in charge of both prudential and conduct of business supervision. The twin peaks approach is based on the separation of regulatory objectives between prudential supervision and consumer protection. Finally, some countries prefer to build a unique hybrid model, seeking to create the most effective supervisory framework by combining characteristics of the above-mentioned four models. The main idea behind this approach is to match the framework to the country's capabilities and unique features.

During the time of the recent global financial crises and afterwards, the global society put a lot of strength and effort into studying the issues of financial regulation and supervision. Governments and 
financial supervision authorities, under pressure from society, declared full-scale reforms of the financial sector and prudential revision of the financial system's structure in order to achieve soundness and stability in the post-crisis period. ${ }^{2}$

Remodeling of financial supervision frameworks appeared to be at the leading edge of those changes, by and large, because at the time, financial supervision architectures actually failed to forecast, prevent, and mitigate the crisis. In fact, due to permanent changes in financial markets and product sophistication, the search for the most suitable supervision framework, capable of facing challenges of the financial system, has never really ended. Another issue is that there is always some long-term gap between the introduction of any financial innovation into the markets and supervisors' reaction to the changes.

The main objectives of this paper are to sum up the practices in the field of financial supervision framework, to examine the relationship between the structure of financial supervision and its quality, and to identify the most effective financial supervisory framework. Although no framework can itself guarantee high-quality supervision, choosing the most effective tool may improve the stability and resilience of financial systems across the world. ${ }^{3}$

The analysis of empirical data in this paper is based on information for 49 countries that belong to G20 group or OECD member countries over the period 1997-2015. The research examines the trends in financial regulation and supervision frameworks. Reviewing the information on individual countries' supervision frameworks, we find a tendency toward combining elements from different supervision models to create a hybrid models as an appropriate financial supervision framework in assuring the safeness and soundness of the financial system.

This research is a response to the efforts of governments and financial supervisory authorities to find the most suitable financial supervision framework to face financial crises and address financial system challenges. ${ }^{4}$ In other words, the findings of the research will make it possible to understand whether any regulation and supervision model can be emphasized as a genuinely effective approach to financial regulation and supervision.

The paper has the following structure. Section 2 reviews the current financial supervision frameworks. In Section 3, the research data and methodology issues are described. In Section 4, the empirical results are presented. Section 5 concludes.

\section{FINANCIAL SUPERVISORY FRAMEWORKS}

Up to the late fifteenth century, economy and finance were considered to be one. At that time, finance was fulfilling its main function of providing funds for economic entities, in its purest form. Since the eighteenth century, the role of finance has risen significantly. At the same time, the size of the financial system has been growing rapidly. According to Carswell (2011), such deep changes, shortly followed by financial market failures, such as the South Sea bubble, led to closer attention being paid to the financial sector by the authorities. ${ }^{5}$ Generally speaking, the stock market crisis only ensured that the financial system and its operation would be regulated, supervised, and monitored. As a result, the system of financial regulation and supervision was improved. From that point, all changes in the financial sector were accompanied by relative changes in financial regulation and supervision. Usually, such changes in regulation are made later, as a response to some market changes (failures).

Since that time, financial regulation and supervision has become the subject of ongoing research and studies. Debates regarding financial regulation in general and forms of financial supervision and its severity in particular have never really ended. After every crisis, such discussions flare up with renewed vigor. Scholars, professionals, international organizations, and policymakers have been wondering about the role of an appropriate supervisory structure in ensuring the soundness of the financial system. According to Goodhart (2010), financial regulation has always been characterized by the a-theoretical, highly practical responses of the authorities to urgent problems to avoid their repetition. In fact, the structure/model of the regulation system, which establishes a number of norms, principles, and requirements, is strongly dependent on understanding what supervision should accomplish. For a long time, the individual risk of institutions has been understood as potentially the biggest danger to the 
stability of the financial system. Consequently, the past system was built in such a way as to minimize that kind of risk. However, as practice has shown, the focus of the supervision on the individual risk of institutions, rather than on systemic risk, has caused further system failure. Goodhart argues that past financial supervision was badly designed and showed its inability to guarantee the soundness of the financial system. Contemporary supervision, in his opinion, should mainly pay attention to systemic externalities and to consumer protection. It is significant that Goodhart has posited the idea of "paradigm shift" that is, the need for fundamental changes in authorities' understanding of the purpose of financial supervision. Such a reconsideration of the goals of financial supervision will cause changes in the tools of regulation; that is, it will transform the financial regulation structure/model.

Among other outstanding research projects, a major role in studying this issue has been played by the World Bank's conferences, research, and papers. The World Bank conference "Aligning Financial Supervisory Structures with Country Needs," which featured more than 70 participants from 52 countries, yielded an eponymous book by Carmichael et al (2004). Summing up the information presented at the conference, the authors conclude that the majority of countries consider the structure of supervision and regulation to be the main aspect of their efficiency and effectiveness. Another important issue mentioned in the book is the fact that although there is no structural model that suits every country perfectly, two polar approaches to building a supervision structure were indicated. On the one hand, there is the traditional sector-by-sector supervision, and on the other hand, there is the full sectoral integration approach. In fact, developed countries tend to have integrated supervision, whereas developing countries favor sectoral financial regulation. There is a need to point out that the structure of the regulation, as the authors observe, also depends heavily on the cultural and legal heritage of the particular country. Besides, there is room for some hard-to-predict factors, which in the end could have some impact on financial regulation models, as the authors point out (for instance, the desire of the authorities to minimize expenditure on the financial regulation structure).

It is worth mentioning that according to Masciandaro and Quintyn (2011), the changes in financial regulation architecture often occurred as responses to financial markets' failures or structural changes in markets. They empirically analyze the evolution of different countries' regulation systems during the period 1998-2009 and conclude that there is a trend of structural change in financial regulation and supervision away from the sectoral model of regulation to the unified (integrated) model. As an outcome of this wave of reform, the supervision landscape was diversified to a greater extent than ever. Although the main push to widespread reforms worldwide came from the UK, where the Financial Services Authority was established in 1998, the UK was not the first country to set up a new model. According to the paper, the Scandinavian countries - Norway, Iceland, Denmark and Sweden - made changes in their financial regulation and supervision models in the late 1980s and early 1990s. Masciandaro and Quintyn also note that due to the recent global financial crisis, the reforms in the regulation and supervision structure are likely to continue, with a shift to models that would be able to provide regulators with exhaustive and up-to-date market information.

The keen interest in the issue of the financial supervision has not just led to an increase in the number of qualitative studies. For instance, Čihák and Tieman (2008) have researched the quality of financial sector regulation and supervision around the world (Eijffinger et al., 2011). While working for the International Monetary Fund, they managed, together with World Bank, to create a unique dataset on the quality of regulation around the globe that includes both theoretical information and detailed assessments of the practical implementation of the commonly accepted international principles and standards for financial sector regulation and supervision in each country. The interesting finding is that, on average, countries' regulatory frameworks fulfill 75 percent of the international standards for financial sector regulation and supervision. However, scholars found that there were serious differences in the quality of financial supervision and regulation across countries: the quality of the financial supervision systems of high-income economies is higher than in low- or medium-income countries, although financial regulators in high-income countries usually have more challenges because their financial systems are more complex.

As the literature review and current practice show, financial supervision structures vary widely across the globe because of countries' historical, political, cultural, economic, and financial dissimilarities. 
Consequently, there is no one model to be used for each country although supervision systems in different countries are dealing with similar issues. In 2008, a G-30 report, "The structure of financial supervision: Approaches and challenges in a global market place," reviewed some national supervisory and regulatory approaches. Starting the study in July 2007, the G-30 studied the evolution of nations' regulation structures. The study identifies four models of financial regulation in use across the globe, namely the institutional, functional, integrated, and "twin peaks" models. In our study, we use this system of classification.

\section{FIGURE 1 \\ FINANCIAL SUPERVISION FRAMEWORKS}

A. Institutional model

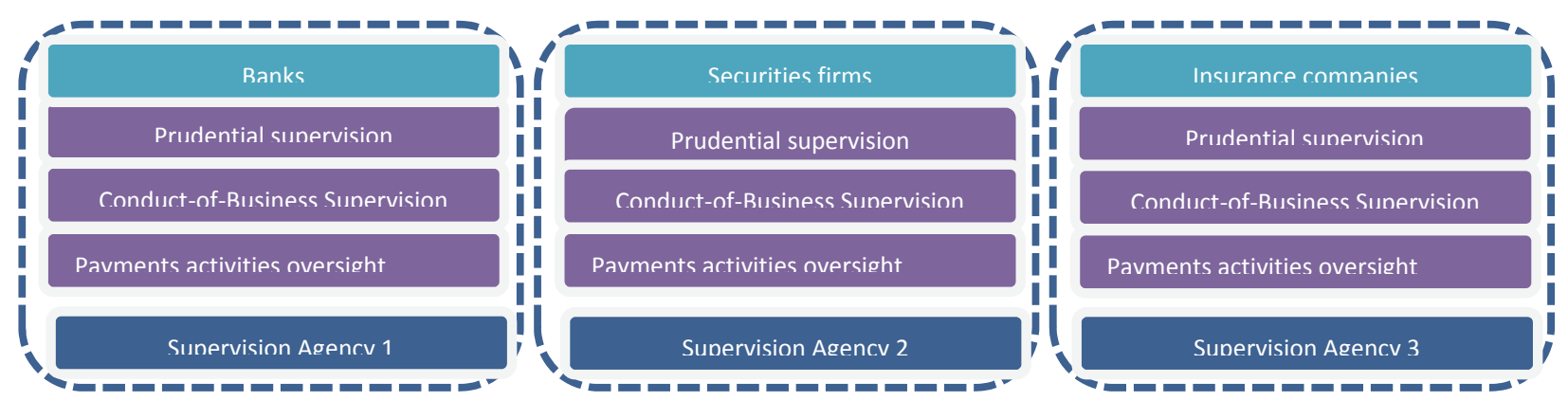

B. Functional model

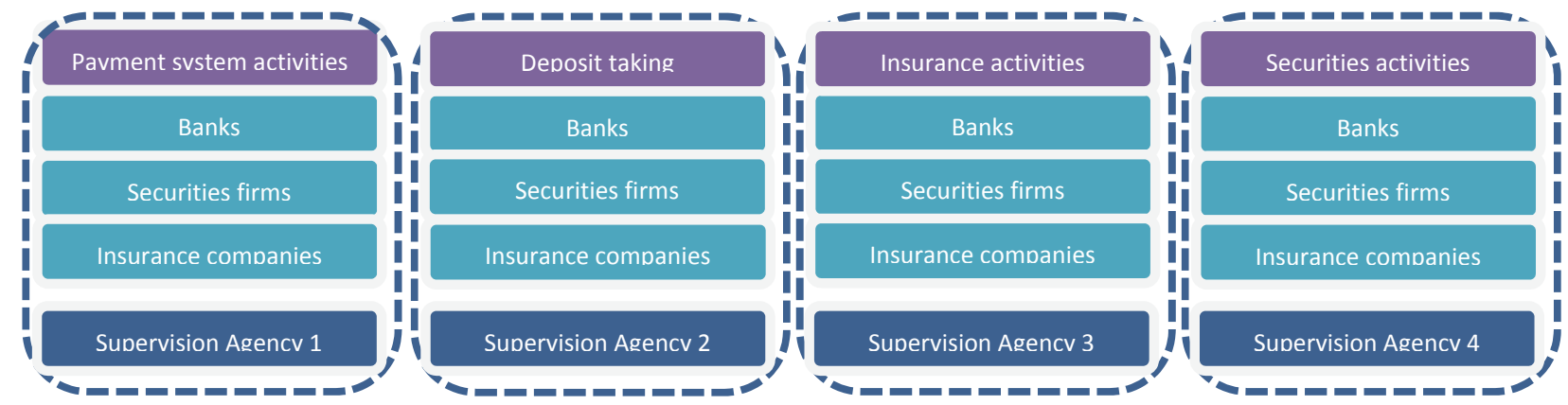

\section{Integrated model}

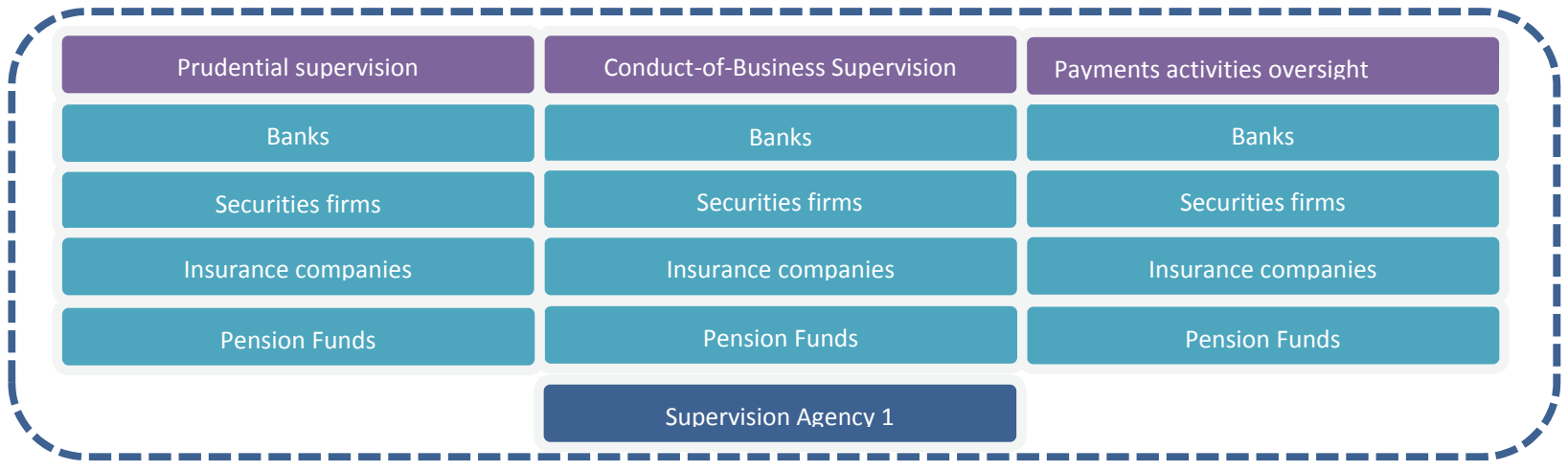




\section{Twin peaks model}

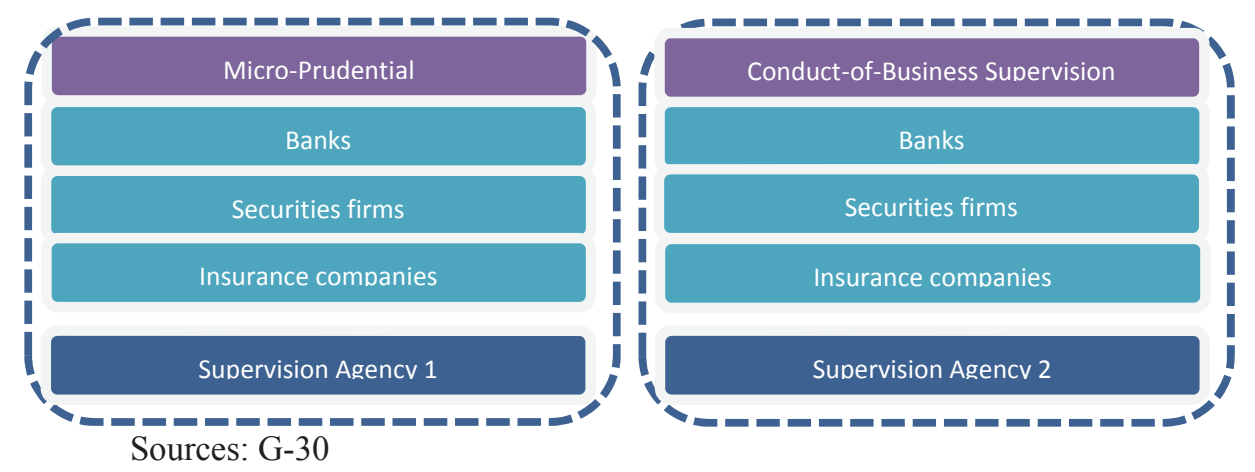

One of the most widely used and common classical financial regulation and supervision frameworks is the Institutional Approach (also known as the sectoral or vertical model). This is an approach driven by the legal status of the supervised objective (entity). Hence, the entity's legal status (for instance, firm registered as an insurance company, bank, etc.) determines which regulator has the duty of supervising its activity from prudential and business conduct perspectives. The legal status also sets the frame of the firm's permitted business activity, although nowadays the activity of a company can be spread across several different markets or even different economic sectors. Such companies are supervised by different regulators; this fact challenges the quality of overall supervision and increases its costs. Other disadvantages of this model are bureaucracy and functional overlap. One important thing is that this approach requires a high level of cooperation between the different regulators to monitor the state of the whole financial system. Owing to its simplicity, this framework is in common use and is applied, for instance, in CIS countries, China, India, etc.

Another framework for financial regulation and supervision is the Functional model. It is true to say that this model in not as common as the previous one. Under this framework, each type of entity's business may be supervised by different regulators regardless of the company's legal status. For instance, if a company performs banking, insurance, and securities activities, each of these businesses would be supervised by a separate regulator responsible for both prudential and business conduct regulation. The main disadvantage of this model is that each regulatory institution has a list of activities to monitor and supervise, so there is a risk of neglect. In addition, there is no full picture of a company with many activities, and thus this approach requires a very high level of cooperation between agencies. This model has been used at various times in Brazil, France, Spain, and Italy.

One of the most reliable supervision frameworks of nowadays is the Integrated approach (see table 3), also known as FSA model because of the well know example of the model in use is the Financial Service Authorities (FSA) in Scandinavian countries. Under this model there is one common institution in charge of both prudential and conduct of business regulation and supervision. It could be either a new institution or a central bank. In general, this model can be useful in smaller financial markets, where the regulation and supervision of the whole financial system can be performed by a single institution, so called mega regulator. The practices of the model in large markets were not effective enough due to failures of regulators to capture large complex financial systems. The advantage of the framework is a straight focus on regulation and supervision without interactions, overlapping and conflict with some other institutions. This approach is more cost efficient, enabling to use consolidated supervision and eliminate the risk of regulatory arbitrage as well. However, this single focus can lead to the risk of regulatory failure, i.e. a break in the "four eyes" principle. Currently, this framework is in use in Germany, Norway, Denmark, Russia, Poland, etc.

Although some scholars classify the model as a Functional approach to financial regulation and supervision, the majority think that "twin peaks" is a form of regulation by objective, i.e., by the type of market failure the regulation is obliged to correct. The main point of objective-oriented regulation is to focus on a desired outcome or objective by having a suitable regulation structure. It gives a measure of 
flexibility to the regulator to reach that goal in the best way apparently available. Thus, this approach is better to respond to changes in the market. Moreover, regulation by objectives can have a synergistic effect in financial regulation by consolidating regulatory responsibility in various areas and can guarantee a higher level of market discipline. The first theoretical overview of the "twin peaks" model was conducted in 1995 by Taylor $(1995,2010)$. This approach appeared as a response to financial market developments. As the borders between banking, the insurance business, and securities disappeared, the traditional sectoral model of regulation became useless. Thus, this model was a way to try to deal with some problems in the regulatory system caused not only by the creation of large financial holdings, but also by the appearance of new types of financial securities/instruments and the bundling and unbundling of various kinds of services/products previously offered by institutionally different types of company (Schooner and Taylor, 2010).

Originally, the "twin peaks" approach was based on the separation of regulation objectives between prudential supervision and conduct-of-business/sales practice (i.e. consumer protection). In reality, it is true to say that the number of objectives can be far more than two. Some scholars have identified four, or even six, goals of financial regulation. However, for the sake of reducing regulation costs, such objectives have been divided into the two above-mentioned groups. In order to perform the above goals, Taylor suggested the appointment of two agencies, independent from the central bank. Dividing the objectives between separate regulatory institutions can minimize the conflict between the contrasting fields, because it may happen that the prudential mandate conflicts with matters of conduct, and the authority may give priority to safety and soundness as these are closely associated with the stability of the financial sector. However, even such a separation would not prevent tensions completely, especially when the prudential issues remain the priority in consumer protection matters.

According to Taylor, even when such a model is launched, the role of central bank remains vital, though its focus shifts from the soundness of individual institutions to maintaining the stability of functioning of sectors of the financial market and their interconnections. First, the central bank keeps fulfilling its function as a main monetary policy authority. At the same time, the bank starts to behave as a crisis manager if needed. Its second main duty is to conduct macro-prudential regulation and supervision, (i.e., to deal with systemic risk, the overall financial structure, the interest rate, payment systems, etc.) and to coordinate the activity of all regulation agencies. It is known that the "twin peaks" approach is more specialized than other regulation models are. Separation of regulation objectives between two agencies allows them to hire employees with relevant competence for their specific functions. For instance, the prudential regulator is able to hire staff with particular kinds of business and financial expertise while the conduct-of-business regulator focuses on employing enforcement-oriented personal. This would improve the overall quality of regulation and supervision. This model has been implemented in Australia and the Netherlands, and its results prove its high effectiveness. Other countries, confident that the model works, have also decided to apply it into the regulation of their financial systems. ${ }^{6}$

Practice in the field shows, however, that some countries prefer to build unique models by mixing some characteristics of the above-mentioned four approaches for the sake of creating the most effective regulation and supervision framework. They create hybrid models that cannot be classified as belonging to any of those four individual models. The main idea behind this approach is to match the framework to the country's capabilities and unique economic, financial, political, cultural, historical, and other features. Canada, the United States, Serbia, Croatia, and France all have hybrid regulation and supervision frameworks.

As the reviewed literature shows, since the time when the financial system emerged as a single system, questions about how to supervise it and what is the most efficient way to do it have generated considerable interest. Society is united in understanding that there is no ideal supervision concept/model, but at the same time, different countries have come to rather similar regulation models. The recent global financial crisis demonstrated some weak points in the financial regulation and supervision frameworks. Thus, the search for a new regulation model began, one more appropriate to the current realities. Today, finding the most effective financial supervision model is a high-priority task not only for scholars and policymakers but also for society as a whole. 


\section{DATA AND METHODOLOGY}

We use country-specific data on regulatory quality, the structure of financial supervision, and banking sector characteristics such as capital ratios, performance and related risks for 49 member countries of the G20 and/or OECD during the period from 1997 to 2015 (see Table 1 for the list of countries and their financial supervisory model). All the data is obtained from the World Bank database, including Worldwide Governance Indicators, World Development Indicators, and Global Financial Development. After examining for correlation between variables, we select 16 variables for this study with correlation coefficients less than 0.2 . See Table 2 for summary statistics. ${ }^{7}$

TABLE 1

LIST OF COUNTRIES AND THEIR FINANCIAL SUPERVISION MODELS

\begin{tabular}{lclc}
\hline Country & Model & Country & Model \\
\hline Argentina & $\mathrm{Ins}$ & Japan & $\mathrm{Int}$ \\
Australia & $\mathrm{TP}$ & Korea, Rep. & $\mathrm{Hb}$ \\
Austria & $\mathrm{Int}$ & Latvia & $\mathrm{Int}$ \\
Belgium & $\mathrm{TP}$ & Lithuania & $\mathrm{Int}$ \\
Brazil & $\mathrm{Hb}$ & Luxembourg & $\mathrm{Hb}$ \\
Bulgaria & $\mathrm{Hb}$ & Malta & $\mathrm{Int}$ \\
Canada & $\mathrm{Hb}$ & Mexico & $\mathrm{Hb}$ \\
Chile & $\mathrm{Hb}$ & Netherlands & $\mathrm{TP}$ \\
China & $\mathrm{Ins}$ & New Zealand & $\mathrm{Hb}$ \\
Croatia & $\mathrm{Hb}$ & Norway & $\mathrm{Int}$ \\
Cyprus & $\mathrm{Ins}$ & Poland & $\mathrm{Int}$ \\
Czech Republic & $\mathrm{Int}$ & Portugal & $\mathrm{Ins}$ \\
Denmark & $\mathrm{Int}$ & Romania & $\mathrm{Hb}$ \\
Estonia & $\mathrm{Int}$ & Russian Federation & $\mathrm{Int}$ \\
Finland & $\mathrm{Int}$ & Saudi Arabia & $\mathrm{Hb}$ \\
France & $\mathrm{Hb}$ & Slovak Republic & $\mathrm{Int}$ \\
Germany & $\mathrm{Int}$ & Slovenia & $\mathrm{Ins}$ \\
Greece & $\mathrm{Hb}$ & South Africa & $\mathrm{Hb}$ \\
Hungary & $\mathrm{Int}$ & Spain & $\mathrm{Hb}$ \\
Iceland & $\mathrm{Int}$ & Sweden & $\mathrm{Int}$ \\
India & $\mathrm{Hb}$ & Switzerland & $\mathrm{Int}$ \\
Indonesia & $\mathrm{Int}$ & Turkey & $\mathrm{Ins}$ \\
Ireland & $\mathrm{Int}$ & United Kingdom & $\mathrm{TP}$ \\
Israel & $\mathrm{Ins}$ & United States & $\mathrm{Hb}$ \\
Italy & $\mathrm{Hb}$ & & \\
\hline
\end{tabular}

Notes: Applied baking supervision models as of 2015: Ins - institutional; Int integrated; Fn - functional; TP- Twin peaks; $\mathrm{Hb}$ - hybrid. 
TABLE 2

SUMMARY STATISTICS

\begin{tabular}{lrrrr}
\hline Variables & Mean & Std. Dev. & Min & Max \\
\hline Bank Z-score & 11.2668 & 7.4192 & -2.71 & 93.74 \\
Country economy (1-advanced, 0-emerging) & 0.6735 & 0.4692 & 0 & 1 \\
Interest rate spread (lending rate minus deposit & 5.6218 & 9.3666 & -6.9125 & 166.1901 \\
rate, \%p) & & & & \\
5-bank asset concentration & 77.2744 & 16.9375 & 25.71 & 100 \\
Bank credit to bank deposits (\%) & 118.559 & 55.8718 & 17.79 & 367.08 \\
Bank nonperforming loans to gross loans (\%) & 5.2623 & 6.3355 & 0.1 & 48.6 \\
Bank regulatory capital to risk-weighted assets (\%) & 14.5815 & 3.8797 & 2.5 & 41.8 \\
Bank return on assets (\%, after tax) & 0.7879 & 1.3075 & -8.52 & 10.74 \\
Banking crisis dummy (1=banking crisis, 0=none) & 0.1633 & 0.3698 & 0 & 1 \\
Foreign banks among total banks (\%) & 33.4681 & 26.4602 & 0 & 96 \\
Lerner index & 0.2164 & 0.1868 & -2.56 & 0.72 \\
Dummy Twin peaks & 0.0430 & 0.2029 & 0 & 1 \\
Dummy Integrated Approach & 0.3050 & 0.4607 & 0 & 1 \\
Dummy Functional Approach & 0.0451 & 0.2077 & 0 & 1 \\
Dummy Institutional (Sectoral) Approach & 0.3136 & 0.4642 & 0 & 1 \\
Dummy Hybrid Approach & 0.2932 & 0.4555 & 0 & 1 \\
\hline
\end{tabular}

Our empirical approach consists of a panel data analysis in order to explain the quality of financial supervision as a function of the financial supervisory framework, controlling for level of economic development and other explanatory variables. As a proxy for the quality of financial supervision, we select the bank Z-score metric provided by the World Bank. ${ }^{8}$ This indicator shows the probability of default of a country's banking system, i.e. banking system resilience. The lower the score, the higher the risk/probability of default of an entity. Consequently, if the financial supervision of a particular country is efficient, the Z-score of the country is high.

In order to examine the impact of each supervisory model on its quality, we introduce a dummy variable for each framework that takes a value of one for countries with a particular approach in use for each observed year and zero for all other supervisory models. To find the information about countries' particular models in use, we use studies by Čihák and Podpiera (2006), Kremers and Schoenmaker (2003), Masciandaro and Quintyn (2015), Oreški and Pavcović (2014), reports and papers from the G-30 (2008 and 2009), and other open sources. ${ }^{9}$

In order to find the relationship between the quality of financial regulation and supervision and the particular framework, we conduct panel data regression as follows (see Equation 1 below):

Z-score ${ }_{i t}=\alpha+\beta_{1}\left(\right.$ Supervisory model dummy $\left._{i t}\right)+\beta_{\mathrm{n}}\left(\right.$ Control variables $\left._{i t}\right)+\varepsilon$;

For control variables, we consider bank-specific characteristics that may affect the probability of default of a country's banking system. They include interest rate spread (lending rate minus deposit rate), top five bank asset concentration, bank credit to bank deposits, bank regulatory capital to risk-weighted assets, bank nonperforming loans to gross loans, bank return on assets, banking crisis dummy indicating one if there a country experienced a banking crisis, foreign banks among total banks, and Lerner index. To control for the level of a country's economic development influencing the quality of financial supervision we add an economic development dummy indicating one for advanced economies and zero for emerging and developing economies.

It is worthwhile to mention that the techniques of assessment and conversion used in the study are not scientifically exact, so some obvious limitations are apparent. For instance, while trying to be as objective as possible in converting and assessing data, there is still room for subjectivity, depending on the tools used, the techniques, and the researcher's experience, etc. Another limitation is in the nature of regulation 
quality itself, as there are some elements that are difficult to quantify. In addition, in using proxy variables, we need to bear in mind that they may not fully reflect main variables.

\section{EMPIRICAL RESULTS}

Table 3 shows the regression results. We find that the effectiveness of the hybrid supervisory framework is statistically higher than that of the institutional framework (used as a reference in the regression) after controlling for other variables. Comparing the magnitude of the coefficients appears to indicate the following order of effectiveness, from highest to lowest: hybrid (0.915), functional (0.867), twin peaks (0.725), integrated (0.565) and institutional (reference). The coefficient of the dummy variable for the hybrid model is 0.915 and statistically significant at the $10 \%$ level. However, the coefficients of dummy variables for the twin peaks, integrated and functional approaches are not statistically significant. This result suggests that no single financial supervisory model is superior to all others in terms of banking system resilience. The best model is specific to each country, and some adjustment of the typical four models may be necessary.

TABLE 3

\section{REGRESSION RESULTS}

\begin{tabular}{|c|c|}
\hline Dependent Variable: Bank Z-score & coefficients \\
\hline Country economy (1-advanced, 0 -emerging) & $\begin{array}{l}3.098 * * \\
(1.801)\end{array}$ \\
\hline Interest rate spread (lending rate minus deposit rate, $\% \mathrm{p}$ ) & $\begin{array}{c}0.057^{* * *} * \\
(0.024)\end{array}$ \\
\hline 5-bank asset concentration & $\begin{array}{c}-0.054 * * * \\
(0.019)\end{array}$ \\
\hline Bank credit to bank deposits (\%) & $\begin{array}{l}-0.003 \\
(0.005)\end{array}$ \\
\hline Bank nonperforming loans to gross loans (\%) & $\begin{array}{l}-0.003 \\
(0.030)\end{array}$ \\
\hline Bank regulatory capital to risk-weighted assets (\%) & $\begin{array}{c}0.156^{* * *} \\
(0.048)\end{array}$ \\
\hline Bank return on assets $(\%$, after tax $)$ & $\begin{array}{c}0.614 * * * \\
(0.130)\end{array}$ \\
\hline Banking crisis dummy ( $1=$ banking crisis, $0=$ none $)$ & $\begin{array}{c}-0.923 * * \\
(0.426)\end{array}$ \\
\hline Foreign banks among total banks (\%) & $\begin{array}{c}-0.018 * \\
(0.014)\end{array}$ \\
\hline Lerner index & $\begin{array}{l}1.307^{*} \\
(0.830)\end{array}$ \\
\hline Dummy Twin peaks & $\begin{array}{c}0.725 \\
(1.201)\end{array}$ \\
\hline Dummy Integrated Approach & $\begin{array}{c}0.565 \\
(0.532)\end{array}$ \\
\hline Dummy Functional Approach & $\begin{array}{c}0.867 \\
(1.074)\end{array}$ \\
\hline Dummy Institutional Approach & reference \\
\hline Dummy Hybrid Approach & $\begin{array}{l}0.915 * \\
(0.600)\end{array}$ \\
\hline Constant & $\begin{array}{l}10.682 \\
(2.174)\end{array}$ \\
\hline $\begin{array}{l}\text { No of observation } \\
\mathrm{R}^{2}\end{array}$ & $\begin{array}{l}931 \\
0.06\end{array}$ \\
\hline
\end{tabular}


We note that the level of economic development has a positive impact on the quality of financial supervision. Among other factors, the quality of supervision is also positively affected by market power in the banking market (measured by the Lerner index), bank profitability (ROA), and the level of banks' regulatory capital. Also, the experience of a financial crisis is associated with a lower quality of financial supervision.

\section{CONCLUSIONS}

This paper examines the effectiveness of five types of supervision model - the institutional, integrated, functional, twin peaks, and hybrid models. We test the impact of a particular model on the effectiveness of financial supervision proxied by probability of default of a country's banking system (Zscore). We find that the effectiveness of the hybrid supervisory framework is statistically higher than that of the institutional framework. The differences in effectiveness of other frameworks are not statistically significant, although the order of effectiveness seems to be, from greatest to least: hybrid, functional, twin peaks, integrated and institutional.

These results should be interpreted with caution. First, the sample is rather limited as we consider only 49 countries due to data availability. Second, there is a possibility of missing some important factors — such as financial development, politics, or even history - affecting the choice of financial supervisory framework. Third, in order to study such an issue, it is better to use some specific measures of financial supervision quality (for instance, Basel Core Principles compliance) rather than proxy indicators which cannot fully explain the performance of financial supervision.

\section{ACKNOWLEDGMENT}

We would like to thank Maude Toussaint-Comeau for her valuable comments on an earlier draft and Hanna Onyschenko for her helpful assistance with this study. The views expressed are only those of the authors and do not necessary reflect those of the Korea Development Institute or the National bank of Ukraine.

\section{ENDNOTES}

1. Carmichael et al (2004) conclude that the majority of countries consider the structure of supervision and regulation to be the main aspect of their efficiency and effectiveness, and there is no structural model that suits every country perfectly.

2. For example, financial supervision became more risk-oriented, while dividing it into micro- and macroprudential areas; capital and liquidity buffers of large financial institutions were strengthened; fast bank resolution mechanism was introduced; and the practices became more transparent keeping the regulators independent at the same time.

3. The study covers questions neither of the role of central banks in the banking supervision, nor appropriate supervision response to a shadow banking issue.

4. Masciandaro and Quintyn (2011) argue that changes in financial regulation architecture often occur as responses to financial market failures or structural changes in markets.

5. A bubble on the UK stock market was caused by manipulation of the South Sea Company's stocks (17191720).

6. See Sohn and Vyshnevskyi (2016) for more details about Twin Peaks approach.

7. As some data in original sample is missing, we use chained multiple imputation (MI) functions in order to keep the appropriate sample size. Predictive mean matching technique is applied for 33 out of 51 variables with 200 imputations iterations (see Rodwell, 2014).

8. Z-score is a risk level measure firstly calculated by Altman (1968) for corporate entities out of companies' specific financial ratios.

9. Other studies use slightly different classifications of the financial supervision model. Carmichael et al. (2004) allocated sector by sector model and fully integration model. Masciandaro and Quintyn (2011) separated vertical (solos) model, horizontal (peaks) model, unified (integrated) model, and hybrid regimes. 
Čihák and Podpiera (2008) classified into full sectoral integration, partial sectoral and no sectoral integration. Calvo et al. (2018) separated sectoral, integrated and partially integrated models.

\section{REFERENCES}

Altman, E. I. (1968). Financial Ratios, Discriminant Analysis and the Prediction of Corporate Bankruptcy. Journal of Finance, 23, 589-609.

Calvo, D., Crisanto, J. C., Hohl, S., \& Gutiérrez, O. P. (2018). Financial Supervisory Architecture: What Has Changed After the Crisis? FSI Insights on policy implementation, No 8. Bank for International Settlements.

Carmichael, J., Fleming, A., \& Llewellyn, D. T. (2004). Aligning financial supervisory structures with country needs. World Bank Institute.

Carswell, J. (2011). The South Sea Bubble Paperback. Literary Licensing.

Čihák, M., \& Podpiera, R. (2008). Integrated Financial Supervision: Which Model? The North American Journal of Economics and Finance, 19, 135-152.

Čihák, M., \& Podpiera, R. (2006). Is One Watchdog Better Than Three? International Experience with Integrated Financial Sector Supervision. The IMF Working Paper, WP/06/57.

Čihák, M., \& Tieman, A. (2008). Quality of Financial Sector Regulation and Supervision around the World. The IMF Working Paper, WP/08/190.

Eijffinger, S., Masciandaro, D., \& Bocconi Uni (2011). Handbook of Central Banking, Financial Regulation and Supervision: after the Financial Crisis. Edward Elgar.

Goodhart, C. (2010). How should we regulate the financial sector? In Turner, Adair et al., The Future of Finance: The LSE Report. London School of Economics and Political Science.

Kremers, J., \& Schoenmaker, D. (2010). Twin Peaks: Experiences in the Netherlands. LSE Financial Markets Group Paper Series.

Kremers, J., Schoenmaker, D., \& Wierts, P. (2003). Cross-sector supervision: which model? BrookingsWharton Papers on Financial Services.

Masciandaro, D., \& Quintyn, M. (2011). Regulating the Regulators: The Changing Face of Financial Supervision Architectures before and after the Financial Crisis. Handbook of Central Banking, Financial Regulation and Supervision. Edward Elgar Publishing.

Masciandaro, D., Pansini, R.V., \& Quintyn, M. (2011). The Economic Crisis: Did Financial Supervision Matter? The IMF Working Paper, WP/11/261.

Masciandaro, D., \& Quintyn, M. (2011). Measuring Financial Regulation Architectures and the Role of the Central Banks. Capco Institute Journal of Financial Transformation, 32, 9-14.

Masciandaro, D., \& Quintyn, M. (2015). The Governance of Financial Supervision: Recent Development. Journal of Economic Surveys, 30, 982-1006.

Oreški, T., \& Pavcović, A. (2014). Global Trends in Financial Sector Supervisory Architectures. Recent Advances in Financial Planning and Product Development, 55-67.

Rodwell, L., Lee, K. J., Romaniuk, H., \& Carlin, J. B. (2014). Comparison of Methods for Imputing Limited-range Variables: A Simulation Study. BMC Medical Research Methodology, 14(57), 111.

Schooner, H. M., \& Taylor, M. W. (2010). Global Bank Regulation: Principles and policies. Elsevier.

Sohn, W., \& Vyshnevskyi, I. (2016). The 'Twin Peaks' Model of Post-crisis Banking Supervision. Applied Economics Letters, 24(8), 571-574.

Taylor, M. (1995). Twin Peaks: A Regulatory Structure for the New Century. London: Centre for the Study of Financial Innovation.

Taylor, M. (2009). Twin Peaks Revisited: A Second Chance for Regulatory Reform. London: Centre for the Study of Financial Innovation.

Taylor, M. (2009). The Road from 'Twin Peaks' - and Way Back. Connecticut Insurance Law Journal, 16(1), 67-88. 